\title{
Effect of acute nitric oxide synthase inhibition in the modulation of heart rate in rats
}

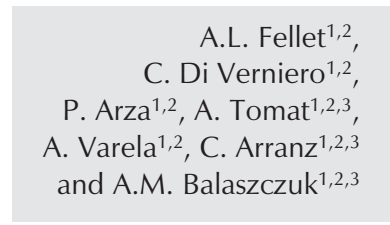

Correspondence

A.L. Fellet

Cátedra de Fisiología

Facultad de Farmacia y Bioquímica

Universidad de Buenos Aires

(1113) Junín, 956, 7o Piso

Buenos Aires

Argentina

Fax: +54-11-4964-8280

E-mail: afellet@huemul.ffyb.uba.ar

Research supported by Universidad de Buenos Aires, Fundación Barceló and IQUIMEFA-CONICET, Buenos Aires, Argentina.

Received July 12, 2002 Accepted January 29, 2003

\begin{abstract}
Acute nitric oxide synthase inhibition with $\mathrm{N}^{\mathrm{G}}$-nitro-L-arginine methyl ester (L-NAME) on chronotropic and pressor responses was studied in anesthetized intact rats and rats submitted to partial and complete autonomic blockade. Blood pressure and heart rate were monitored intra-arterially. Intravenous L-NAME injection $(7.5 \mathrm{mg} / \mathrm{kg})$ elicited the same hypertensive response in intact rats and in rats with partial (ganglionic and parasympathetic blockade) and complete autonomic blockade $(38 \pm 3,55 \pm 6,54 \pm 5,45 \pm 5 \mathrm{mmHg}$, respectively; $\mathrm{N}=9$, $\mathrm{P}=\mathrm{NS}$ ). L-NAME-induced bradycardia at the time when blood pressure reached the peak plateau was similar in intact rats and in rats with partial autonomic blockade $(43 \pm 8,38 \pm 5,46 \pm 6 \mathrm{bpm}$, respectively; $\mathrm{N}=9, \mathrm{P}=\mathrm{NS})$. Rats with combined autonomic blockade showed a tachycardic response to L-NAME $(10 \pm 3 \mathrm{bpm}, \mathrm{P}<0.05$ vs intact animals, $\mathrm{N}=9$ ). Increasing doses of L-NAME (5.0, 7.5 and 10 $\mathrm{mg} / \mathrm{kg}, \mathrm{N}=9$ ) caused a similar increase in blood pressure (45 \pm 5 , $38 \pm 3,44 \pm 9 \mathrm{mmHg}$, respectively; $\mathrm{P}=\mathrm{NS})$ and heart rate $(31 \pm 4$, $34 \pm 3,35 \pm 4 \mathrm{bpm}$, respectively; $\mathrm{P}=\mathrm{NS})$. Addition of L-NAME (500 $\mu \mathrm{M})$ to isolated atria from rats killed by cervical dislocation and rats previously subjected to complete autonomic blockade did not affect spontaneous beating or contractile strength $(\mathrm{N}=9)$. In vivo results showed that L-NAME promoted a tachycardic response in rats with complete autonomic blockade, whereas the in vitro experiments showed no effect on intrinsic heart rate, suggesting that humoral mechanisms may be involved in the L-NAME-induced cardiac response.
\end{abstract}

Key words - Nitric oxide

- Nitric oxide synthase

- Autonomic nervous system

- Heart rate

- Heart

\section{Introduction}

Although the role of nitric oxide $(\mathrm{NO})$ in modulating myocardial contractility has been extensively investigated, the effects of $\mathrm{NO}$ on heart rate (HR) have received comparatively little attention $(1,2)$. There is evidence that NO plays an obligatory role in cholin- ergic modulation of automaticity in isolated myocytes $(3,4)$ and that it participates in vagal control of HR in intact mammals $(5,6)$. Some studies have suggested that NO may alter channel mechanisms at the sinoatrial node and other cardiac cells $(7,8)$. However, the cholinergic regulation of $\mathrm{NO}$ pathways in cardiac function remains controversial and 
the data in the literature are contradictory. Previous investigations have demonstrated that NO donors may directly stimulate the pacemaking activity of the sinoatrial node, independently of the arterial baroreflex (9), and others have reported that the NO pathway may inhibit L-type calcium channel and cAMP-stimulated hyperpolarization-activated current $\left(I_{\mathrm{f}}\right)(10)$.

Despite intensive research in this area, however, there are many questions about the underlying mechanisms by which NO modulates $\mathrm{HR}$, in particular whether interactions exist between the NO pathways and the autonomic nervous system (ANS) in this situation (11-13).

Given the contradictory data about the relations between ANS and myocardial cell NO in the control of HR, the present study was performed to investigate the effects of acute administration of $\mathrm{N}^{\mathrm{G}}$-nitro-L-arginine methyl ester (L-NAME) on the modulation of HR in intact rats, in rats submitted to partial and complete autonomic blockade, and in isolated rat atria.

\section{Material and Methods}

Male Sprague-Dawley rats (230 to $260 \mathrm{~g}$ body weight) from the breeding laboratories of the Facultad de Veterinaria (Universidad de Buenos Aires, Argentina) were used for each experimental group throughout all experiments. Rats were housed in a humidityand temperature-controlled environment with an automatic 12/12-h light/dark cycle. Rats were fed standard rat chow from Nutrimentos Purina (Buenos Aires, Argentina) and received tap water ad libitum up to the day of the experiments. Animals were used in compliance with the research animal use guidelines of the American Heart Association.

\section{In vivo studies}

Rats were anesthetized intraperitoneally (ip) with urethane $(1.0 \mathrm{~g} / \mathrm{kg}$ body weight)
(Sigma, St. Louis, MO, USA) and anesthesia was maintained with supplemental ip doses throughout the experiment. A tracheotomy was performed and an endotracheal tube (3.5 or $4 \mathrm{~mm}$ ID, Portex) was inserted $4 \mathrm{~cm}$ into the trachea and secured. After performing the tracheotomy, a polyethylene cannula was inserted into the right and left femoral vein for phenylephrine (PE) infusion and drug administration, respectively. Mean arterial pressure (MAP) was measured directly with a cannula inserted into the right femoral artery and connected to a pressure transducer. The blood pressure signal was measured continuously with a Statham P23 ID pressure transducer (Gould Instruments, Cleveland, OH, USA) and recorded with a polygraph (Physiograph E \& M Co. Inc., Houston, TX, USA). HR was derived from the pulsatile pressor signal via tachographic beat to beat conversion with a tachograph preamplifier (577-26 tachometer, Coulbourn Instruments, Inc., Allentown, PA, USA). Body temperature was monitored with a rectal probe and was maintained at $37.0 \pm 0.5^{\circ} \mathrm{C}$ with heating lamps. Data were obtained with a data acquisition program (Labtech Notebook, Laboratory Technologies, Wilmington, MA, USA).

\section{Experimental design}

Protocol I: Effects of L-NAME (7.5 mg/ $\mathrm{kg}$ ) on MAP and HR in intact, ganglionic, vagotomized and anesthetized rats with complete autonomic blockade. The rats were divided into four groups. Group 1, nine rats with intact ANS and with no previous treatment; group 2, nine rats submitted to ganglionic blockade by administration of an intravenous (iv) bolus of $10 \mathrm{mg} / \mathrm{kg}$ hexamethonium (Sigma); group 3, nine rats submitted to parasympathetic blockade by bilateral vagotomy at the supraclavicular level; group 4, nine rats submitted to combined hexamethonium administration $(10 \mathrm{mg} / \mathrm{kg}, i v)$ and bilateral vagotomy to guarantee the blockade of 
both sympathetic and parasympathetic traffic.

In groups 2 and 4 the administration of hexamethonium was repeated every $20 \mathrm{~min}$ to ensure complete blockade of ganglionic transmission during the experiments. Also, PE (4-6 $\mu \mathrm{g} \mathrm{kg}^{-1} \mathrm{~min}^{-1}, i v$; Sigma) was infused during the experiment to maintain MAP within the basal range before L-NAME administration $(13,14)$.

MAP and HR were monitored continuously in all groups. The effects of L-NAME $(7.5 \mathrm{mg} / \mathrm{kg}$; Sigma) on MAP and HR were studied by comparing the values obtained 5 min before and after its administration. In addition, in group 4 the pressor and chronotropic responses to L-NAME were also assessed when HR reached the maximum change after L-NAME injection. In additional experiments ( 9 rats with complete autonomic blockade), a bolus of PE (6 $\mu \mathrm{g} / \mathrm{kg}$, $i v$ ) was used to determine the specificity of the response to acute L-NAME administration on the cardiovascular parameters.

Protocol II: Effects of different doses of L-NAME on MAP and HR in rats submitted to complete autonomic blockade. The pressor response to L-NAME was monitored in rats submitted to complete autonomic blockade using increasing doses of L-NAME, i.e., $5.0,7.5$ and $10 \mathrm{mg} / \mathrm{kg}, \mathrm{N}=9$ per group. The animals were studied after complete autonomic blockade with hexamethonium (10 $\mathrm{mg} / \mathrm{kg}, i v)$ and bilateral vagotomy. The administration of hexamethonium and the infusion of PE were as described in protocol I. MAP and HR were recorded continuously over a period of 60 min after L-NAME administration. Maximum HR and MAP changes after L-NAME injection were used to indicate the magnitude of the response.

\section{In vitro studies}

Group 1. Nine male Sprague-Dawley rats (230 to 260 g body weight) were killed by cervical dislocation and the hearts were re- moved as quickly as possible.

Group 2. Before cervical dislocation, nine anesthetized male Sprague-Dawley rats (230 to $260 \mathrm{~g}$ body weight) were subjected to complete autonomic blockade as described for the in vivo experiments.

The atria from groups 1 and 2 were excised and mounted isometrically under a resting tension of $750 \mathrm{mg}$ in 20-ml organ baths. The bathing medium was a KrebsRinger bicarbonate solution, $\mathrm{pH} 7.40 \pm 0.05$, of the following composition: $120 \mathrm{NaCl}, 25$ $\mathrm{mM} \mathrm{NaHCO}$, $4.8 \mathrm{mM} \mathrm{KCl}, 1.33 \mathrm{mM}$ $\mathrm{MgSO}_{4}, 1.2 \mathrm{mM} \mathrm{KH}{ }_{2} \mathrm{PO}_{4}, 1.6 \mathrm{mM} \mathrm{CaCl}$, $0.02 \mathrm{mM} \mathrm{CaNa}_{2}$ EDTA and $10 \mathrm{mM}$ dextrose. The solution was continuously bubbled with $95 \% \mathrm{O}_{2}-5 \% \mathrm{CO}_{2}$ and the temperature was kept at $31{ }^{\circ} \mathrm{C}$. The contraction frequency of spontaneously beating atria was measured from 30-s samples of recorded contractions. After a 60-min recovery period the isolated atria were exposed to L-NAME $(500 \mu \mathrm{M})$ and subsequent recordings were obtained at 2, 10 and $30 \mathrm{~min}$.

\section{Statistical analysis}

Data are reported as means \pm SEM and were analyzed statistically by one-way analysis of variance followed by the Bonferroni test. In some cases, the unpaired Student $t$ test was applied. The 5\% probability level was used as a criterion for significance. The Prism software (Graph Pad Software, San Diego, CA, USA) was used for statistical analysis.

\section{Results}

\section{In vivo studies}

Protocol I. Basal MAP and HR values were similar in all groups of animals. Group $1=83 \pm 3 \mathrm{mmHg}, 349 \pm 9 \mathrm{bpm}$; group $2=82$ $\pm 4 \mathrm{mmHg}, 322 \pm 23 \mathrm{bpm}$; group $3=88 \pm 7$ $\mathrm{mmHg}, 460 \pm 15 \mathrm{bpm}$; group $4=83 \pm 6$ $\mathrm{mmHg}, 349 \pm 19 \mathrm{bpm}(\mathrm{P}=\mathrm{NS})$. 
No differences were observed in the pressor response to a single bolus injection of LNAME $(7.5 \mathrm{mg} / \mathrm{kg})$ in the four experimental groups of animals (Figure 1). The effects of L-NAME on HR in the four experimental groups are shown in Figure 2. L-NAMEinduced bradycardia at the time when MAP reached the peak plateau was of similar magnitude in intact animals and in animals submitted to ganglionic blockade and vagotomy. In contrast, L-NAME administration induced tachycardia after complete autonomic blockade. Moreover, we observed that in group 4 the maximum tachycardic effect was reached
Figure 1. $A$, Change in mean arterial pressure (MAP) induced by $\mathrm{N}^{G}$-nitro-L-arginine methyl ester (L-NAME). Acute iv L-NAME (7.5 $\mathrm{mg} / \mathrm{kg}$ ) significantly increased MAP and this response was similar in intact rats (group 1) and in rats with sympathetic (group 2), parasympathetic (group 3) and complete autonomic blockade (group 4). Data are reported as means \pm SEM for 9 rats in each group. There were no statistically significant differences between groups (one-way analysis of variance followed by the Bonferroni test). B, Representative tracing of raw data obtained in one experiment for each group showing the effect of LNAME $(7.5 \mathrm{mg} / \mathrm{kg}$, iv) on MAP.

Figure 2. $A$, Heart rate (HR) response to $\mathrm{NG}^{\mathrm{G}}$-nitro-L-arginine methyl ester (L-NAME, 7.5 $\mathrm{mg} / \mathrm{kg}, i \mathrm{v}$ ) in intact rats (group 1) and in rats with sympathetic (group 2), parasympathetic (group 3) and complete autonomic blockade (group 4). The LNAME-induced bradycardia in response to a similar increase in MAP was quantitatively similar in intact, sympathectomized and vagotomized rats. This effect was abolished by complete autonomic blockade. Acute iv injection of L-NAME increased HR in group $4\left({ }^{*} \mathrm{P}<0.05\right.$ vs group 1 , unpaired Student $t$-test). Data are reported as means \pm SEM for 9 rats in each group. $B$, Representative tracing of raw data obtained in one experiment for each group showing the effect of L-NAME $(7.5 \mathrm{mg} / \mathrm{kg}$, iv) on HR.
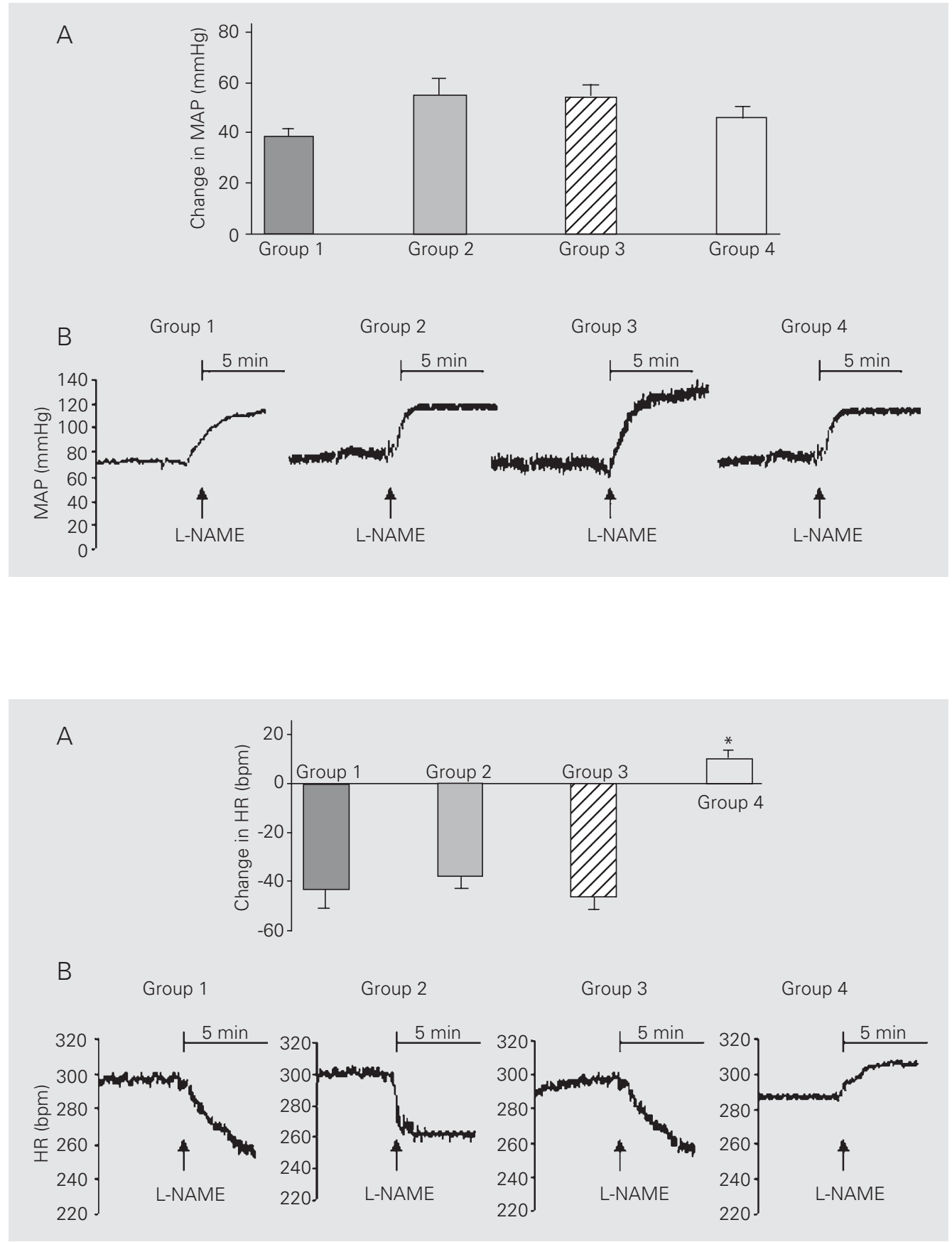
at about 30 min after $i v$ L-NAME administration, from a mean pre-L-NAME value of $288 \pm 13$ to $322 \pm 10 \mathrm{bpm}$ after L-NAME injection $(\mathrm{P}<0.05)$.

In completely autonomically blocked rats treated with a bolus injection of PE we observed a similar increase in MAP compared with L-NAME administration in group 4 ( $\triangle \mathrm{MAP}$ at $30 \mathrm{~min}: 49 \pm 4$ vs $45 \pm 5 \mathrm{mmHg}$, respectively, $\mathrm{P}=\mathrm{NS}$ ). However, HR was unchanged $30 \mathrm{~min}$ after PE administration $(361 \pm 17$ vs $391 \pm 18$ bpm before PE, respectively, $\mathrm{P}=\mathrm{NS}$ ).

Protocol II. Table 1 shows changes in MAP and HR after different doses of LNAME $(5.0,7.5$ and $10 \mathrm{mg} / \mathrm{kg})$ in rats submitted to complete autonomic blockade. There were no significant differences in the magnitude of increase in MAP and HR obtained with the doses tested.

\section{In vitro studies}

The data shown in Table 2 indicate that L-NAME did not affect the pacemaker activity of isolated atria. Table 3 shows that the contractile strength was also unchanged by L-NAME compared to basal values.

\section{Discussion}

In vivo protocols were used to study the effects of the NO synthase inhibitor L-NAME on MAP and HR of anesthetized rats submitted to partial and complete autonomic blockade. MAP and HR were similar in all groups of animals at the beginning of the experiments, reflecting similar hemodynamic conditions. A bolus injection of L-NAME (7.5 $\mathrm{mg} / \mathrm{kg}$ ) increased MAP similarly in intact rats and in rats submitted to ganglionic, parasympathetic and complete autonomic blockade. This suggests that the effect of L-NAME administration on blood pressure is independent of sympathetic or parasympathetic influences and is probably due to a direct vasoconstrictor effect caused by the decrease of vascular NO synthesis. This result agrees with published data demonstrating that the NO-dependent systemic vasodilatation occurs in the absence of a functional ANS $(13,15)$. Furthermore, we have found that at the same time that MAP reached the maximum increase, L-NAME also induced a bradycardic response in intact, vagotomized

Table 1. Effects of increasing doses of L-NAME on changes in mean arterial pressure $(\triangle \mathrm{MAP})$ and heart rate $(\Delta \mathrm{HR})$ after complete autonomic blockade.

\begin{tabular}{lccc}
\hline & \multicolumn{3}{c}{ L-NAME $(\mathrm{mg} / \mathrm{kg})$} \\
\cline { 2 - 4 } & 5.0 & 7.5 & 10.0 \\
\hline$\Delta \mathrm{MAP}(\mathrm{mmHg})$ & $45 \pm 5$ & $38 \pm 3$ & $44 \pm 9$ \\
$\Delta \mathrm{HR}(\mathrm{bpm})$ & $31 \pm 4$ & $34 \pm 3$ & $35 \pm 4$ \\
\hline
\end{tabular}

L-NAME was acute intravenously injected. Data are reported as means \pm SEM for 9 rats in each group. There were no statistically significant differences among the responses to different doses (one-way analysis of variance followed by the Bonferroni test).

Table 2. Chronotropic response to L-NAME by isolated atria.

\begin{tabular}{lcccc}
\hline & \multicolumn{4}{c}{ Time (min) } \\
\cline { 2 - 5 } & Basal & 2 & 10 & 30 \\
\hline Group 1 & $160 \pm 6$ & $155 \pm 6$ & $158 \pm 7$ & $151 \pm 5$ \\
Group 2 & $161 \pm 5$ & $156 \pm 4$ & $153 \pm 5$ & $150 \pm 4$ \\
\hline
\end{tabular}

The concentration of L-NAME in the bath was $500 \mu \mathrm{M}$. Data are reported as means \pm SEM bpm for 9 rats in each group. Group 1: cervical dislocation; group 2: complete autonomic blockade + cervical dislocation. There were no statistically significant differences among the responses as a function of time (one-way analysis of variance followed by the Bonferroni test).

Table 3. Inotropic response to L-NAME by isolated atria.

\begin{tabular}{lccc}
\hline & \multicolumn{3}{c}{ Time (min) } \\
\cline { 2 - 4 } & 2 & 10 & 30 \\
\hline Group 1 & $107 \pm 16$ & $109 \pm 18$ & $109 \pm 20$ \\
Group 2 & $108 \pm 18$ & $110 \pm 16$ & $111 \pm 15$ \\
\hline
\end{tabular}

The concentration of L-NAME in the bath was $500 \mu \mathrm{M}$. Data are reported as means \pm SEM for percent of the basal peak developed tension recorded at the end of the stabilization period. $\mathrm{N}=9$ rats per group. Groups 1 and 2 are the same as in Table 2 . There were no statistically significant differences among the responses as a function of time (one-way analysis of variance followed by the Bonferroni test). 
and ganglionic blockaded animals. In contrast, a significant increase in HR was observed in rats with total autonomic blockade. We observed that PE did not induce any increase in HR, confirming the fact that only L-NAME caused an increase in HR in complete autonomic blockaded animals. Since the abolition of baroreflex function in rats with complete autonomic blockade is not the cause of L-NAME-induced tachycardia, we were able to assess the chronotropic response to L-NAME independently of the baroreflex response.

The rise in blood pressure that activates baroreceptor afferents results in both direct and indirect activation of the parasympathetic vagal innervations of the heart, decreasing HR in intact and ganglionic blockaded rats. When both vagus nerves are sectioned, the bradycardic response still occurs and this chronotropic response may be due to the inhibition of sympathetic tone (16).

Focusing on the immediate L-NAMEinduced tachycardia, we determined whether this chronotropic effect persisted in the 5- to $10-\mathrm{mg} / \mathrm{kg}$ dose range of the NO synthase inhibitor. The results showed that the different doses of L-NAME used caused a similar increase in MAP and HR in rats with complete autonomic blockade. The tachycardic effect of L-NAME on these animals was perhaps surprising. Other studies have shown contradictory results with respect to the chronotropic effects of NO synthase inhibition (17) and the antimuscarinic properties of LNAME in in vivo experiments (18). The mechanism responsible for the L-NAMEinduced tachycardia in rats with autonomic blockade is unclear. The results obtained in the present study, which disagree with others $(9,10,13,18)$ may be due, at least in part, to differences in some methodological conditions and/or to differences in the autonomic tone of the animals.

NO synthase has been shown to be present in many sites of the central and peripheral nervous system and is involved in the autonomic control of cardiovascular function $(19,20)$. Recent studies have indicated that changes of NO in the central nervous system may contribute to the regulation of the cardiovascular system by inhibition of the sympathetic nervous system and modulation of the arterial baroreflex (21). Additionally, previous reports have demonstrated that 30 to $60 \mathrm{~min}$ are required for $i v \mathrm{~L}$ NAME to cross the blood-brain barrier and reach a sufficient concentration in the central nervous system to inhibit more than $50 \%$ of central neuronal NO synthase activity in the brain $(22,23)$. The chronotropic response induced by L-NAME reached a maximum value at about 30 min after L-NAME administration, suggesting that the activation of humoral mechanisms (endothelins, angiotensin II, atrial natriuretic peptide, thyroid hormones and others) as well as physical factors such as shear stress or a direct effect of L-NAME may be probably involved in the HR response (24-26).

Thus, based on our findings in in vivo experiments, we evaluated the effect of LNAME on pacemaker and contractile activity in in vitro studies. To assess the possible similarity of autonomic conditions between in vivo and in vitro experiments, a complete autonomic blockade was induced before cervical dislocation. The data showed that the addition of L-NAME at a dose equivalent to that used in vivo did not modify the chronotropic or inotropic effects under our experimental conditions. The L-NAME-induced tachycardia observed in in vivo experiments may not be due to a direct action of the inhibitor on the pacemaker. In isolated right atria, Riado et al. (27) showed that L-NAME did not affect the beat rate, whereas others have reported that low doses of an NO donor or 8-bromo-cGMP increase the spontaneous beating of isolated guinea pig atria and rabbit sinoatrial node cells by activation of the hyperpolarization inward current $(28,29)$. In addition, NO can elicit either positive or negative inotropic effects $(30,31)$. At pres- 
ent, it is unclear how the intrinsic rate depends on NO production within cardiac cells and many in vitro and in vivo studies have illustrated the multiple and sometimes contradictory effects of NO pathways on cardiac function.

We have shown that: a) an acute L-NAME bolus of $7.5 \mathrm{mg} / \mathrm{kg}$ induced the same pressor response in all experimental groups of animals, and this hypertensive effect of LNAME was independent of the ANS; b) acute L-NAME administration to intact, vagotomized and ganglionic blockaded rats promoted bradycardia associated with an increase in blood pressure; c) $i v$ injection of L-
NAME in rats with complete autonomic blockade induced an immediate positive chronotropic effect; d) L-NAME administration had no direct effect on the spontaneous beating or contractile activity of in vitro isolated atria; e) humoral and physical factors may be probably involved in the LNAME-induced response.

\section{Acknowledgments}

The authors wish to thank Ana María Bento Schneider, Associate Teacher of English at the School of Medicine, Universidad de Buenos Aires, Argentina.

\section{References}

1. Kelly RA, Balligand JL \& Smith TW (1996). Nitric oxide and cardiac function. Circulation Research, 79: 363-380.

2. Shah A (1996). Paracrine modulation of heart cell function by endothelial cells. Cardiovascular Research, 31: 847-867.

3. Balligand JL, Kelly RA, Marsden PA, Smith TW \& Michel T (1993). Control of cardiac muscle cell function by an endogenous nitric oxide signaling system. Proceedings of the National Academy of Sciences, USA, 90: 347-351.

4. Han X, Shimoni Y \& Giles WR (1994). An obligatory role for nitric oxide in autonomic control of mammalian heart rate. Journal of Physiology, 476: 309-314.

5. Conlon K, Collins T \& Kidd C (1996). Modulation of vagal actions on heart rate produced by inhibition of nitric oxide synthase in the anesthetized ferret. Experimental Physiology, 81: 547-550.

6. Elvan A, Rubar M \& Zipes DP (1997). NO modulates autonomic effects on sinus discharge rate and AV nodal conduction in openchest dogs. American Journal of Physiology, 272: H263-H271.

7. Vandecasteele G, Eschenhagen T \& Fischmeister R (1998). Role of the NO-cGMP pathway in the muscarinic regulation of the L-type $\mathrm{Ca}^{2+}$ current in human atrial myocytes. Journal of Physiology, 506: 653-663.

8. Gallo MP, Ghigo D, Bosia A, Alloatti G, Costamanga C, Penna C \& Levi RC (1998). Modulation of guinea pig cardiac L-type calcium current by nitric oxide synthase inhibitors. Journal of Physiology, 506: 639-651.

9. De Marco T, Dae M, Yeun-Green MSF et al. (1995). lodine-123 metaiodobenzylguanidine scintigraphic assessment of the transplanted human heart: evidence for late reinnervation. Journal of the American College of Cardiology, 25: 927-931.

10. Sears CE, Choate JK \& Paterson DJ (1998). Inhibition of nitric oxide synthase slows the heart rate recovery from cholinergic activation. Journal of Applied Physiology, 84: 1596-1604.

11. Lacolley PJ, Lewis SJ \& Brody MJ (1991). Role of sympathetic nerve activity in the generation of vascular nitric oxide in urethane-anesthetized rats. Hypertension, 17: 881-887.
12. Toda N, Kitamura Y \& Okamura T (1993). Neural mechanism of hypertension by nitric oxide synthase inhibitor in dogs. Hypertension, 21: 3-8.

13. Pegoraro AA, Carretero OA, Sigmon DH \& Beierwaltes WH (1992). Sympathetic modulation of endothelium-derived relaxing factor. $\mathrm{Hy}$ pertension, 19: 643-647.

14. Vargas HM, Ignarro LJ \& Chaudhuri G (1990). Physiological release of nitric oxide is dependent on the level of vascular tone. European Journal of Pharmacology, 190: 393-397.

15. Radaelli A, Mircoli L, Perlini S, Bolla G, Mori LL, Mancia G \& Ferrari AU (1998). Lack of autonomic contributions to tonic nitric oxidemediated vasodilatation in unanesthetized free-moving rats. Journal of Hypertension, 16: 55-61.

16. Kandel ER, Schwartz JH \& Jessel TM (1991). Principles of Neural Science. 3rd edn. Appleton \& Lange, Norwalk, CT, USA.

17. Scrogin KE, Hatton DC, Chi Y \& Luft FC (1998). Chronic nitric oxide inhibition with L-NAME: effects on autonomic control of the cardiovascular system. American Journal of Physiology, 274: R367-R374.

18. Koss MC (1997). Effect of $N(G)$-nitro-L-arginine methyl ester on functionally characterized muscarinic receptors in anesthetized cats. European Journal of Pharmacology, 335: 199-204.

19. Bredt DS, Hwang PM \& Snyder SH (1990). Localization of nitric oxide synthase indicating a neural role for nitric oxide. Nature, 347 : 768-770.

20. Dun NJ, Dun SL \& Forstermann U (1994). Nitric oxide synthase immunoreactivity in rat pontine medullary neurons. Neuroscience, 59: 429-445.

21. Zanzinger J, Czachurski J \& Seller H (1997). Neuronal nitric oxide reduces sympathetic excitability by modulation of central glutamate effects in pigs. Circulation Research, 80: 565-571.

22. ladecola C, Xu X, Zhang F, Hu J \& el-Fakahany EE (1994). Prolonged inhibition of brain nitric oxide synthase by short-term systemic administration of nitro-L-arginine methyl ester. Neurochemical Research, 19: 501-505.

23. Traystman RJ, Moore LE, Helfaer MA, Davis S, Banasiak K, Williams 
M \& Hurn PD (1995). Nitro-L-arginine analogues: dose- and timerelated nitric oxide synthase inhibition in brain. Stroke, 26: 864-869.

24. Dzau VJ (1993). The role of mechanical and humoral factors in growth regulation of vascular smooth muscle and cardiac myocytes. Current Opinion in Nephrology and Hypertension, 2: 27-32.

25. Masullo P, Venditti P, Agnisola C \& Di Meo S (2000). Role of nitric oxide in the reperfusion induced injury in hyperthyroid rat hearts. Free Radical Research, 32: 411-421.

26. Stepp DW, Merkus D, Nishikawa Y \& Chilian WM (2001). Nitric oxide limits coronary vasoconstriction by a shear stress-dependent mechanism. American Journal of Physiology, 281: H796-H803.

27. Riado SR, Zanesco A, Barker LA, De Luca IMS, Antunes E \& De Nucci G (1999). Long-term nitric oxide inhibition and chronotropic responses in rat isolated right atria. Hypertension, 34 (Part 2): 802807.

28. Musialek P, Lei M, Brown HF, Paterson DJ \& Casadei B (1997). Nitric oxide can increase heart rate by stimulating the hyperpolarization-activated inward current, If. Circulation Research, 81: 60-68.

29. Musialek P, Paterson DJ \& Casadei B (1999). Changes in extracellular $\mathrm{pH}$ mediate the chronotropic responses to L-arginine. Cardiovascular Research, 43: 712-720.

30. Mohan P, Brutsaert DL, Paulus WJ \& Sys SU (1996). Myocardial contractile response to nitric oxide and cGMP. Circulation, 93: 12231229.

31. Kojda G \& Kottenberg K (1999). Regulation of basal myocardial function by NO. Cardiovascular Research, 41: 514-523. 